\title{
Relations among expression of CXCR4, histological patterns, and metastatic potential in adenoid cystic carcinoma of the head and neck
}

\author{
YUSUKE ZUSHI $^{1}$, KAZUMA NOGUCHI $^{1}$, SUSUMU HASHITANI ${ }^{1}$, KAZUNARI SAKURAI $^{1,2}$, \\ EMI SEGAWA ${ }^{1}$, KAZUKI TAKAOKA ${ }^{1}$, YUKIYO TOYOHARA ${ }^{1}$, NORIAKI TANAKA ${ }^{1}$, \\ HIROMITSU KISHIMOTO $^{1}$ and MASAHIRO URADE ${ }^{1}$ \\ ${ }^{1}$ Department of Oral and Maxillofacial Surgery; ${ }^{2}$ Department of Surgical \\ Pathology, Hyogo College of Medicine, Nishinomiya, Hyogo, Japan
}

Received July 10, 2008; Accepted September 2, 2008

DOI: $10.3892 /$ ijo_00000102

\begin{abstract}
Adenoid cystic carcinoma (ACC) may acquire a chemokine-mediated mechanism during the process of metastasis. To investigate the involvement of chemokines in metastasis from ACC, expression of CXCR4 in surgical specimens of ACC and two tumor lines transplantable to nude mice was examined immunohistochemically. In addition, the expression levels of CXCR4 protein and mRNA were examined by Western blotting and reverse-transcription polymerase chain reaction. Our results showed that patients whose tumors expressed high levels of CXCR4 had metastases to the regional lymph nodes and the lung, resulting in poor outcomes. ACCs showing a solid or cribriform pattern with distant metastasis were strongly positive for CXCR4, while those showing a tubular or cribriform pattern without metastasis were weakly positive for CXCR4. In the in vivo model, ACCY tumor showed increasing expression levels of CXCR4 with tumor growth, and the histological pattern changed from cribriform to solid. The histological pattern of ACCI, associated with spontaneous metastasis to the neck, changed from cribriform to undifferentiated carcinoma and was highly metastatic to the lung. This tumor showed high levels of CXCR4 protein and mRNA. These results suggest that CXCR4 expression, histological patterns, and metastatic potential are closely related in ACC.
\end{abstract}

\section{Introduction}

Salivary gland tumors rarely arise in the head and neck region. Among these tumors, adenoid cystic carcinoma

Correspondence to: Dr M. Urade, Department of Oral and Maxillofacial Surgery, Hyogo College of Medicine, 1-1, Mukogawacho, Nishinomiya, Hyogo 663-8501, Japan

E-mail: uradem@hyo-med.ac.jp

Key words: adenoid cystic carcinoma, head and neck, histological patterns, metastasis, CXCR4, chemokine
(ACC) accounts for $\sim 1 \%$ of all head and neck tumors (1). ACC is a generally slow-growing, but highly malignant salivary gland neoplasm with high risks of invasion and metastasis. Histologically, ACC is classified into three subtypes: tubular, cribriform, and solid (2). The clinical behavior of ACC is considered to be related to these histological patterns (3). Tubular or cribriform patterns are associated with better outcomes and survival rates, than the solid pattern $(4,5)$. The majority of ACC, regardless of histological pattern, give rise to metastasis after excision of the primary tumor, negatively affecting outcomes. The lung has a predilection for distant metastasis from ACC (4-6); the mechanism involved is not fully understood.

Tumor metastasis is the most common cause of death in patients with cancer. The migration of cancer cells from the primary tumor to a secondary site is a complex process involving invasion, trafficking, localization, growth, and angiogenesis. CXCR4 is a receptor for stromal cell-derived factor- $1 \alpha$ (SDF-1 $\alpha$; termed CXCL12), a chemokine expressed in several tissues and organs, including the skin, lymph nodes, lung, liver, and bone marrow (7-10). SDF-1 $\alpha$ stimulates cell adhesion, migration, and activation (10-15). CXCR4 has been reported to be expressed on different tumor cell lines $(7,16)$. Melanoma cells expressing CXCR4 have a higher potential for pulmonary metastasis than their CXCR4negative counterparts in a B16 murine melanoma model $(17,18)$. Furthermore, CXCR4 has been documented to play key roles in metastases from breast cancer and melanoma $(7,19)$. Given the complexity of metastasis, it is essential to use experimental models to examine the relationship between the histological characteristics of ACC and the expression of CXCR4.

Recently, we have successfully established two human tumor lines from ACC of the oral floor. These tumor lines show a cribriform pattern histologically and are serially transplantable in nude mice $(20,21)$. In this study, we examined the immunohistochemical expression of CXCR4 in clinical specimens of ACC and in the transplantable tumor lines. We also discussed the relationships among the CXCR4 expression, histological patterns, and metastatic potential of ACC. 


\section{Materials and methods}

Patients and tissue specimens. We studied the clinical and histological characteristics (age, gender, primary site, TNM classification, stage, histological pattern, metastasis, outcome, observation period, CXCR4 grade) of 16 patients with ACC who presented at the Hyogo College of Medicine Hospital (Table I). Nine of the patients were men, and 7 were women. At the time of diagnosis, their ages ranged from 41 to 72 years (mean, 56 years). Surgically excised tissue specimens were obtained from all 16 primary ACCs before treatment. Normal submandibular glands were used as a control. The study was approved by the Ethics Committees of our college, and informed consent was obtained from all patients before sample acquisition. Tumor size and extent of metastasis were assessed according to the TNM classification of malignant tumors, proposed by the International Union against Cancer in 2002 (22).

Histopathological diagnosis was made by two pathologists unexposed to all information on the patients. The histological pattern of each tumor was classified as tubular, cribriform, or solid type according to the World Health Organization Classification of Tumours: Pathology and Genetics of the Head and Neck Tumours (23). Where different histological types coexisted in the same tumor, the predominant type was evaluated.

Detection of pulmonary metastasis. Pulmonary metastasis was assessed on chest radiography and computed tomography (CT) of the lung every 6 months. In addition, ${ }^{67} \mathrm{Ga}$ scintigraphy or positron emission tomography (PET) was performed once a year. Lymph node metastasis was determined on the basis of physical examination and CT findings. All patients were followed up until deceased or for $>5$ years.

ACC tumor lines. Three ACC tumor lines, ACCY (case 5), ACCI (case 6) and ACCIM; the latter of which was derived from cervical metastatic lesion of ACCI in a nude mouse as previously described $(20,21)$, were studied. All animal experiments were performed in compliance with the Guide lines for Animal Experiments of the Hyogo College of Medicine. Briefly, the ACCY tumor line grew rapidly during serial passages. Histologically, $30 \%$ of the cribriform pattern at passage 1 became a solid pattern at passage 15 , and the PCNA labeling index increased 4-fold. In nude mice with ACCI tumors, spontaneous metastasis to the neck developed at passage 2, and the histological pattern changed from a cribriform pattern to undifferentiated carcinoma. The metastatic tumor designated as ACCIM was associated with a high frequency of spontaneous metastasis to the lung when transplanted subcutaneously to nude mice.

Histological and immunohistochemical examinations. Tumor tissues were fixed in $10 \%$ formalin, embedded in paraffin, cut into $4-\mu \mathrm{m}$ sections, and stained with hematoxylin and eosin (H\&E) for histological examination. Immunohistochemical examinations were performed using the avidinbiotin-peroxidase complex (ABC) staining method (24). Briefly, the specimens were treated with $3 \% \mathrm{H}_{2} \mathrm{O}_{2}$ in methanol for 5 min to block endogenous peroxidase activity.

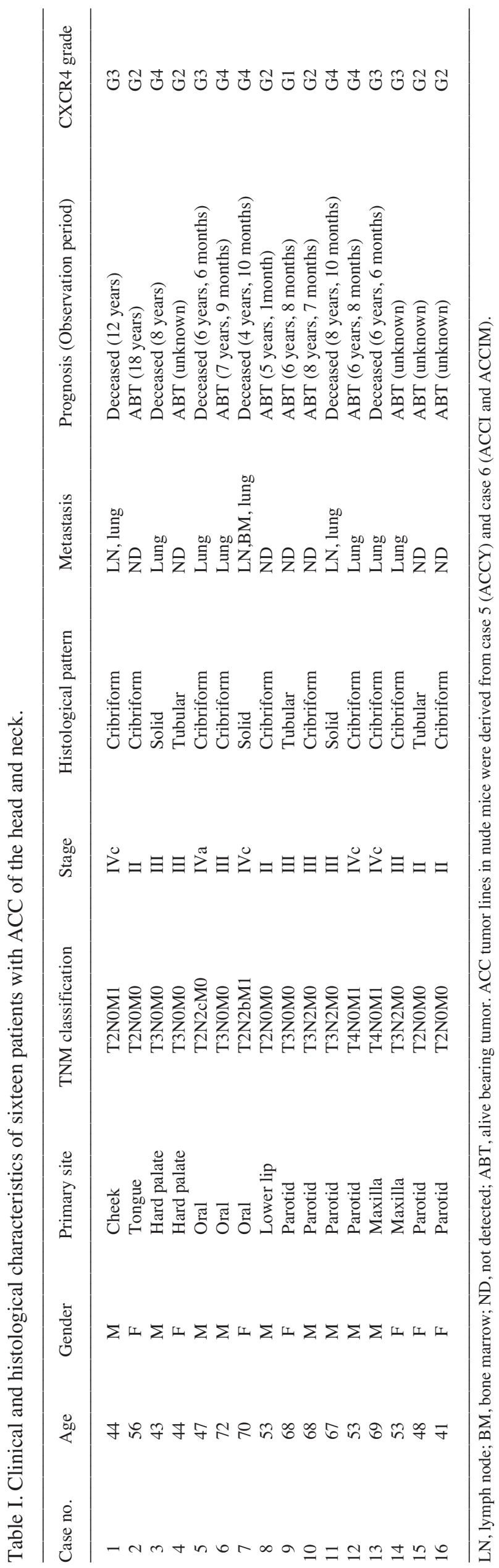



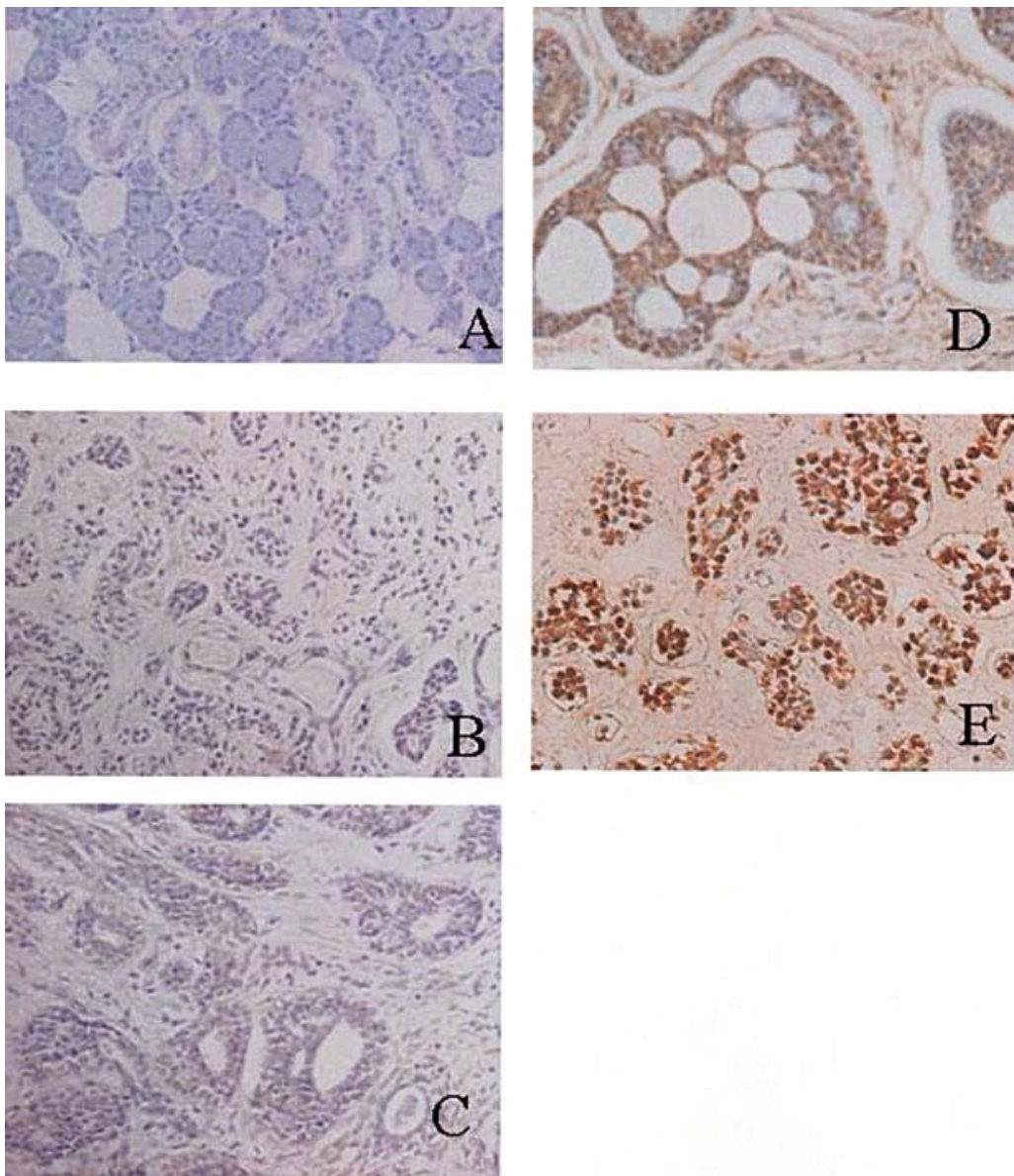

Figure 1. Representative immunohistochemistry of CXCR4 (original magnification, x200). (A) Normal submandibular gland showing grade 0, (B) tubular pattern showing grade 1 (case 9), (C) cribriform pattern showing grade 2 (case 10), (D) cribriform pattern showing grade 3 (case 5 ), (E) solid pattern showing grade 4 (case 3 ).

The specimens were then washed and treated with $1 \%$ normal horse serum in PBS for $15 \mathrm{~min}$. After washing with PBS, the specimens were incubated with monoclonal antibodies against hCXCR4 (R\&D Systems Inc., Minneapolis, MN, USA). After washing again with PBS, the specimens were incubated with ABC complex solution (Vectastain, Vector Lab., Burlingame, CA, USA) at room temperature for 15 min. The specimens were washed with PBS, biotinylated goat anti-mouse IgG (Vector) was applied, and incubated for $30 \mathrm{~min}$ at room temperature. Then, the specimens were treated with a substrate solution containing 3,3'-diaminobenzidine tetrahydrochloride (Wako Pure Chemical Industries, Ltd., Osaka, Japan) and $\mathrm{H}_{2} \mathrm{O}_{2}$ for $\sim 5$ min. Finally, the specimens were counterstained with hematoxylin, dehydrated, and mounted with glycerol gelatin.

Immunohistochemical evaluation. The sections were scored for reaction intensity. The proportions of cells with positive membranous and cytoplasmic staining for CXCR4 were graded as follows: grade 0 intensity (undetectable or negligible expression), no tumor cells positive for immunoreactivity; grade 1 intensity (low expression), 1-25\% positive; grade 2 intensity (intermediate expression), 26-50\% positive; grade 3 intensity (high expression), $51-75 \%$ positive; or grade 4 intensity (high expression), $\geq 76 \%$ positive.
Protein preparation and Western blot analysis. The tumor tissues were lysed in a lysis buffer composed of $\mathrm{Mg}^{2+}$ - and $\mathrm{Ca}^{2+}$ - free phosphate-buffered saline PBS- supplemented with $20 \mathrm{mM}$ Tris- $\mathrm{HCl}$, pH 8.0, 1\% NP40, $150 \mathrm{mM} \mathrm{NaCl}, 1 \mathrm{mM}$ EDTA, $10 \%$ glycerol, $0.1 \%$ B-mercaptoethanol, $0.5 \mathrm{mM}$ dithiothreitol, and a mixture of proteinase inhibitors consisting of $1 \mathrm{mM}$ phenylmethylsulfonyl fluoride, $10 \mu \mathrm{g} / \mathrm{ml}$ aprotinin, $5 \mu \mathrm{g} / \mathrm{ml}$ leupeptin, $5 \mathrm{mM}$ benzamidine, $1 \mu \mathrm{g} / \mathrm{ml}$ pepstatin, $2 \mu \mathrm{g} / \mathrm{ml}$ antipain hydrochloride (Boehringer Mannheim, Mannheim, Germany), $50 \mu \mathrm{M}$ 4-(2-aminoethyl)benzenesulfonyl fluoride hydrochloride (Wako), $2 \mathrm{mM}$ sodium orthovanadate (Sigma-Aldrich Co., St. Louis, MO, USA), and $20 \mathrm{U} / \mathrm{ml}$ ulinastatin (Mochida Pharmaceutical, Tokyo, Japan). The lysate containing $30 \mu \mathrm{g}$ protein was electrophoresed on a 10-20\% gradient SDS-PAGE mini gel (Dai-ichi Kagaku, Tokyo, Japan) and blotted onto a PVDF membrane using Multiphor II (Amersham Pharmacia Biotech, Buckinghamshire, UK) for $30 \mathrm{~min}$. The blotted membrane was blocked with $5 \%$ skim milk in $10 \mathrm{mM}$ Tris$\mathrm{HCl}$, pH 7.2, containing $150 \mathrm{mM} \mathrm{NaCl}$ and $0.5 \%$ Tween-20 and incubated with the primary antibodies $(0.1-1 \mu \mathrm{g} / \mathrm{ml})$ described below at $4^{\circ} \mathrm{C}$ for $16 \mathrm{~h}$. The membrane was then incubated with the alkaline phosphatase-conjugated secondary antibodies $(0.02 \mu \mathrm{g} / \mathrm{ml})$ described below, for $4 \mathrm{~h}$ at room temperature. The membrane was rinsed and treated 

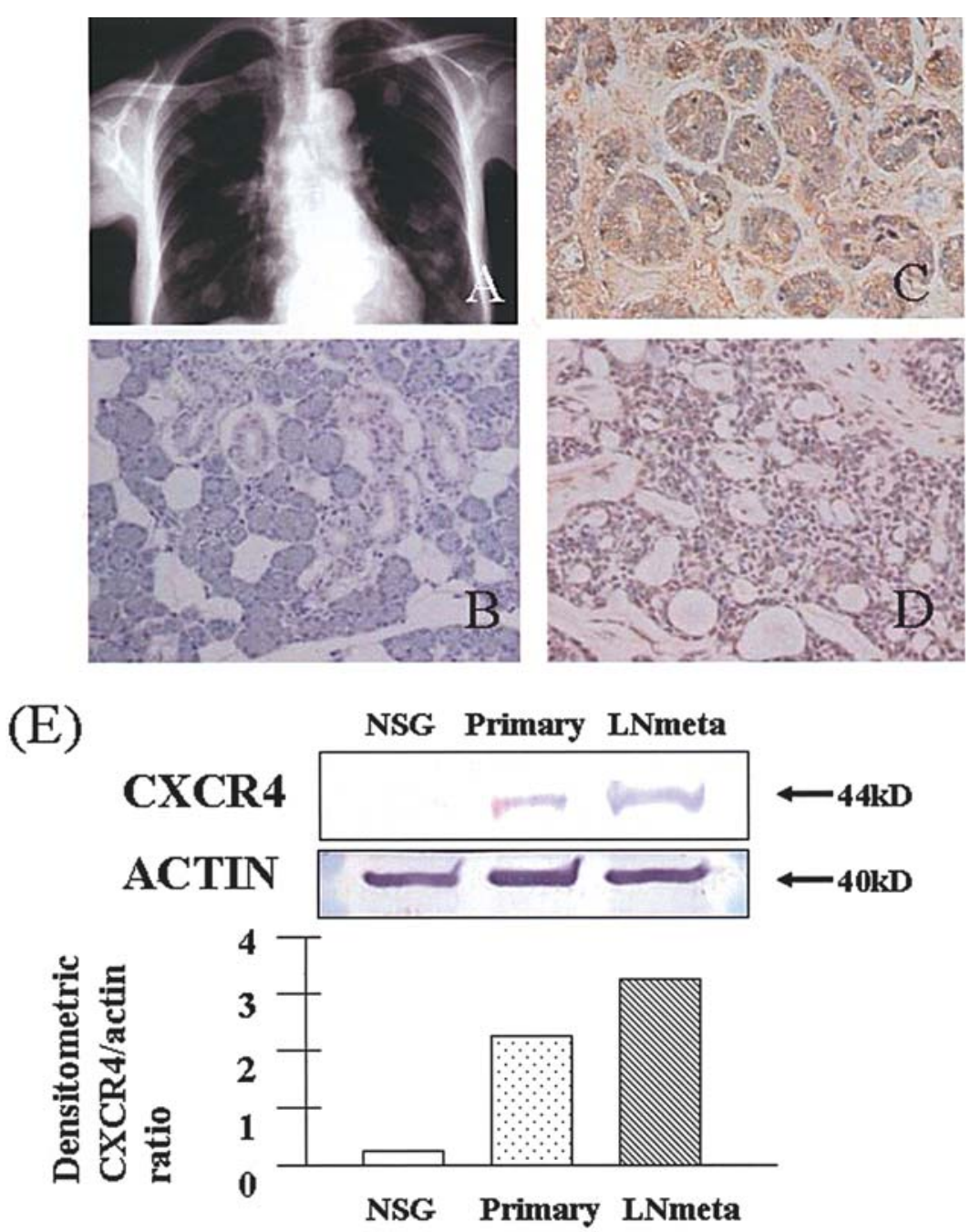

Figure 2. Immunohistochemistry and Western blotting for CXCR4 in case 7 (original magnification, x200). (A) Multiple lung metastasis on X-ray film, (B) normal submandibular gland, grade 0, (C) primary tumor with solid pattern, grade 4, (D) metastatic lymph node, and (E) Western blot of specimens from normal submandibular glands (NSG), primary tumor, and lymph node metastatic tumor (LN meta).

with nitroblue tetrazolium (Sigma-Aldrich) and 5-bromo-4chloro-3-indolyl phosphate (Sigma-Aldrich) to visualize protein bands. The primary antibodies used were mouse anti-hCXCR4 (R\&D Systems Inc.) and mouse polyclonal antibodies against human actin (Santa Cruz Biotechnology, Santa Cruz, CA, USA). The secondary antibodies used were anti-mouse IgG conjugated with alkaline phosphatase (Santa Cruz). The intensity of each band was measured with a densitometer and normalized to that of the actin band.

$R N A$ preparation and reverse-transcription polymerase chain reaction ( $R T-P C R)$. Total RNA was isolated from fresh tumor tissues with the use of Isogen (Nippon Gene Co., Tokyo, Japan), treated with RNase-free DNase (Promega Co., Tokyo, Japan) at $37^{\circ} \mathrm{C}$ for $10 \mathrm{~min}$, and then extracted with phenol-chloroform. To examine differences in the mRNA expression of CXCR4, RT-PCR was performed as follows. PCR of GAPDH cDNA was conducted using a GAPDH-sense primer, 5'-GGTGAAGGTCGGAGTCA ACGG-3', and an antisense primer, 5'-GGTCATGAGTCC TTCCACGAT- $3^{\prime}$, at $94^{\circ} \mathrm{C}$ for $5 \mathrm{~min}$, followed by 30 cycles at $95^{\circ} \mathrm{C}$ for $30 \mathrm{sec}$, at $63^{\circ} \mathrm{C}$ for $30 \mathrm{sec}$, at $72^{\circ} \mathrm{C}$ for $1 \mathrm{~min}$, and finally at $72^{\circ} \mathrm{C}$ for $7 \mathrm{~min}$. The primers for human CXCR 4 were sense, 5'-GGCCCTCAAGACCACAGTCA-3', and antisense, 5'-TTAGCTGGAGTGAAAACTTGAAG-3'. PCR was performed at $94^{\circ} \mathrm{C}$ for $5 \mathrm{~min}$, followed by 35 cycles at $94^{\circ} \mathrm{C}$ for $30 \mathrm{sec}$, at $60^{\circ} \mathrm{C}$ for $30 \mathrm{sec}$, at $72^{\circ} \mathrm{C}$ for $1 \mathrm{~min}$, and finally at $72^{\circ} \mathrm{C}$ for $7 \mathrm{~min}$. PCR products were electrophoresed on agarose gels, stained with ethidium bromide, and visualized under ultraviolet illumination.

\section{Results}

Analysis of clinical cases. Immunohistochemically, CXCR4 expression was found in all 16 cases of ACC. CXCR4 positive cells were observed in all 3 patterns of ACC, whereas normal submandibular glands (NSG) showed negative or weak staining (Fig. 1A). CXCR4 was expressed weakly in nearly all cells of tubular pattern (Fig. 1B), whereas some cells in peripheral areas around pseudocysts of cribriform pattern were moderately positive for CXCR4 (Fig. 1C). Many tumor cells in cribriform pattern (Fig. 1D) and in solid pattern (Fig. 1E) were strongly positive for CXCR4. Nine (56.2\%) of the 16 patients with ACC showed grade 3 or 4 

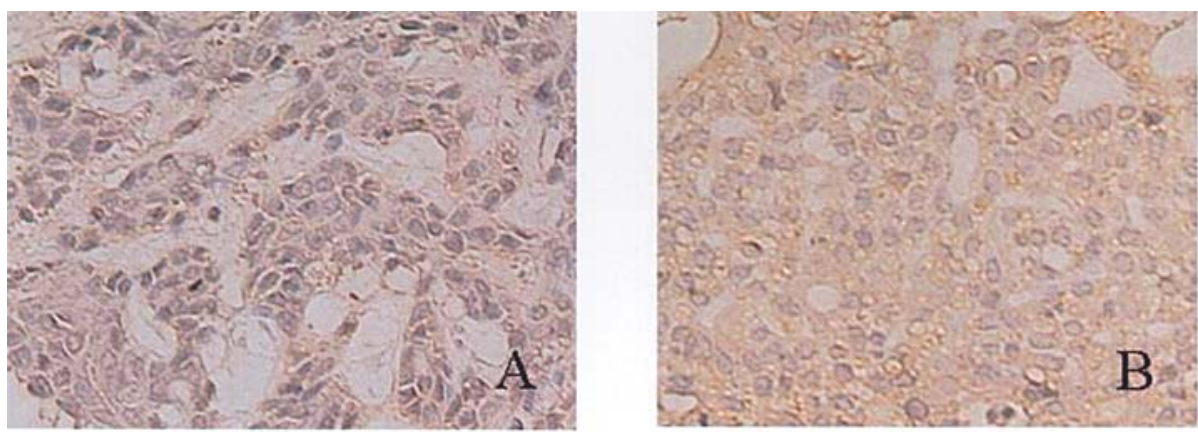

(C) initial 15th

CXCR4
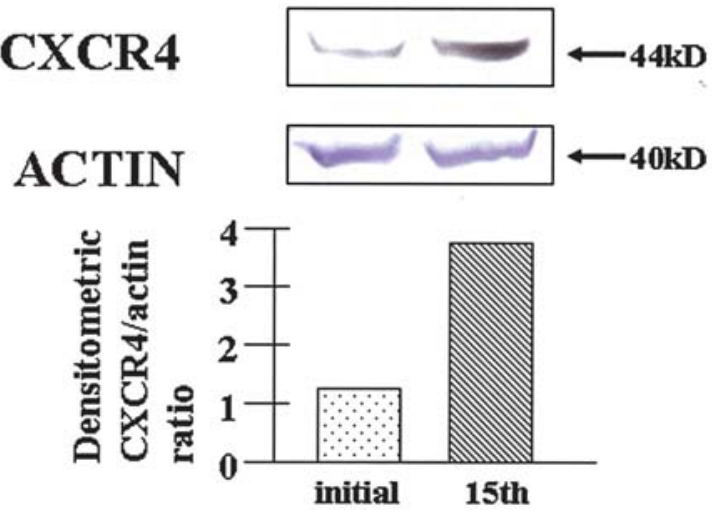

Figure 3. CXCR4 expression by the ACCY tumor line in nude mice. Immunohistochemistry of the ACCY tumor at passage 1 (A) and passage 15 (B) (original magnification, x200). (C) Western blot analysis of CXCR4 protein in the ACCY tumor at passages 1 and 15.

expression of CXCR4 and had lung metastasis. Three $(33.3 \%)$ of these 9 patients had regional lymph node metastasis, and $5(55.6 \%)$ of the 9 patients succumbed to the disease. Seven $(43.8 \%)$ of the 16 patients with grade 1 or 2 expression of CXCR4 had no metastasis and were alive bearing tumors during follow-up. Three patients with a solid pattern had metastases to the lung and lymph nodes, resulting in mortality. Metastases to bone marrow were observed in only one patient with grade 4 expression (case 7) (Table I).

In case 7 with metastases to the lung and regional lymph nodes (Fig. 2A), the expression level of CXCR4 in lymph node metastases was high as well as that in the primary lesion on immunohistochemical analysis (Fig. 2C and D). Concerning Western blotting, expression of CXCR4 in the lymph node metastases was $\sim 1$.4-fold higher than that in the primary lesion (Fig. 2E).

Expression of CXCR4 in ACC tumor cell lines transplanted to nude mice. CXCR4 expression was examined immunohistochemically for ACCY (case 5), ACCI (case 6), and its metastatic tumor line, ACCIM. CXCR4-positive cells were observed in all ACC tumor lines in nude mice. In ACCY, immunohistochemical expression of CXCR4 was higher at passage 15 than at passage 1 (Fig. 3A and B). Similar results were obtained using Western blotting, and the CXCR4 protein level at passage 15 was $\sim 3$-fold higher than that at passage 1 (Fig. 3C). As for ACCI and ACCIM, CXCR4 expression was higher in ACCIM than in ACCI (Fig. 4A and B) and was strongly positive in pulmonary metastatic lesions immunohistochemically. Nests of tumor cells at the lesion border showed particularly strong CXCR4 expression (Fig. 4C, arrows). On RT-PCR analysis, ACCI and ACCIM showed similar, high levels of human CXCR4 mRNA (Fig. 4D). Concerning Western blot analysis, the CXCR4 protein level was $\sim 1.8$-fold higher in ACCIM than in ACCI (Fig. 4E).

\section{Discussion}

Metastasis arises following the spread of cancer cells from a primary site and leads to the formation of new tumors in other organs. Once metastatic lesions are established, treatments are often ineffective. The metastatic process consists of many sequential steps and is not a random event. Different cancer cell types have their own preferential sites for metastasis (7). Although a number of molecules have been shown to have roles in metastasis, the precise mechanism governing the migration and invasion of tumor cells into specific organs is not fully understood.

The chemokine receptor CXCR4 and its cognate ligand CXCL12 have recently received considerable attention because this receptor-ligand system reportedly determines the destination of breast cancer and other types of tumor cells (7). CXCL12 is expressed constitutively in a wide variety of tissues (25) and is also expressed in submandibular lymph nodes (26).

Some studies have suggested a role of the CXCL12/ CXCR4 system in lymph node metastasis (27). Other studies have suggested that the CXCL12/CXCR4 system does not 

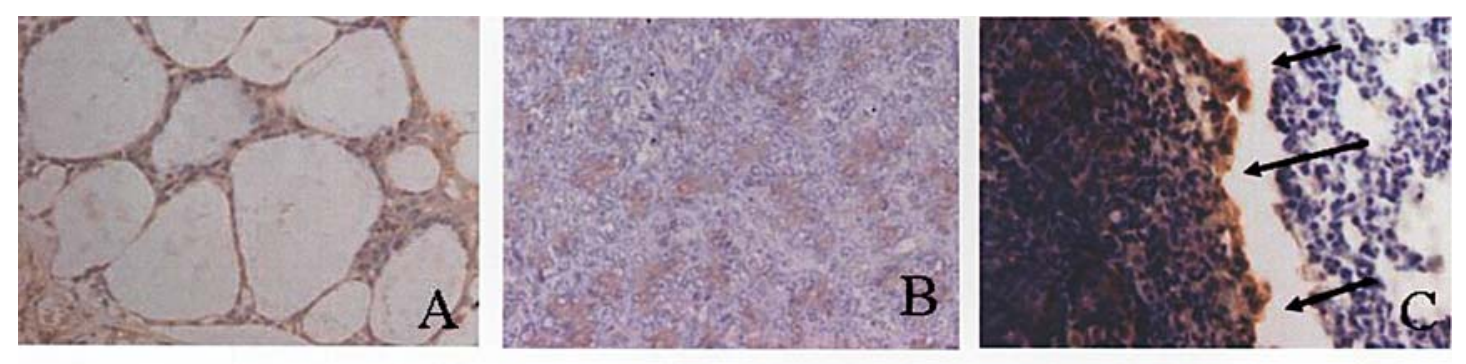

(D)

NSG ACCI ACCIM
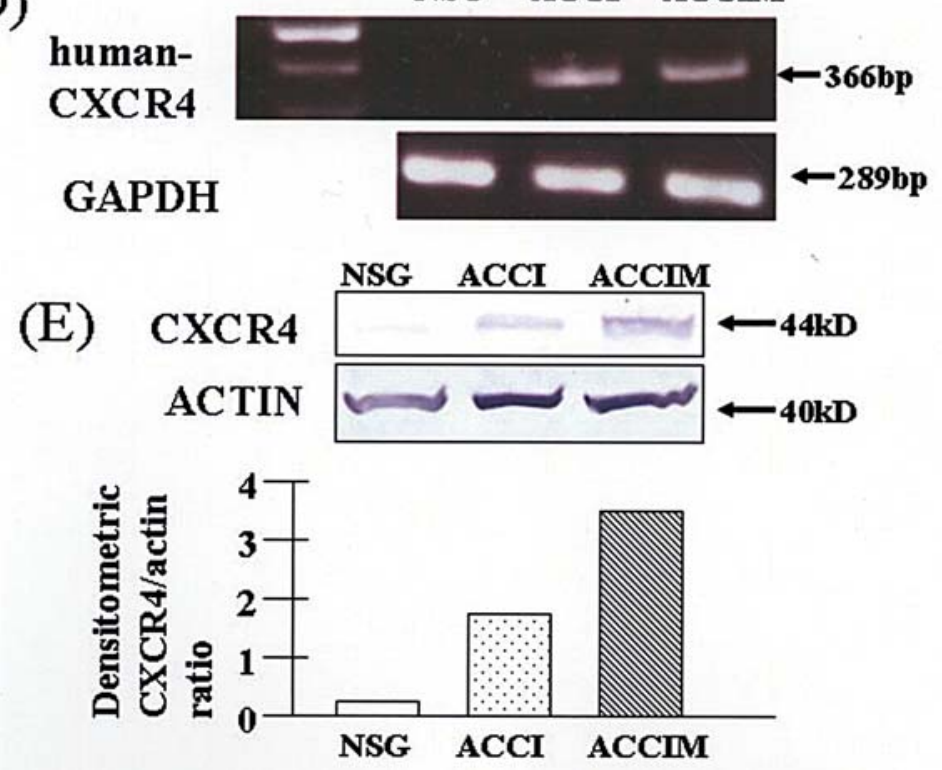

Figure 4. CXCR4 expression of the ACCI tumor line in nude mice. Immunohistochemical staining of CXCR4. (A) ACCI, (B) ACCIM, and (C) lung metastasis from ACCIM (original magnification, x200). Nests of tumor cells at the lesion border showed strong CXCR4 expression (arrows). (D) RT-PCR analysis of human CXCR4 in the ACCI and ACCIM tumors. (E) Western blot analysis of CXCR4 protein in the ACCI and ACCIM tumors.

play a major part in lymphatic tumor spread from metastasis in oral squamous cell carcinoma (28). The role of the CXCL12/CXCR4 system in ACC has been reported only by Müller et al (29). They found that CXCR4 was the only chemokine receptor highly expressed by ACC cell lines, and its signaling led to the induction of directional tumor cell migration, supporting a role of CXCR4 in tumor invasion and survival.

On the basis of currently available evidence, we hypothesized that ACC acquires a chemokine-mediated mechanism during the process of metastasis. In this study, we immunohistochemically analyzed the expression of CXCR4 in ACC. To our knowledge, no previous study has attempted to evaluate the relationship between the expression of CXCR4 and the metastatic potential of ACC, using clinical specimens and serially transplantable ACC tumor lines in nude mice. We immunohistochemically detected CXCR4 protein expression in 16 patients with $\mathrm{ACC}$, as well as in two in vivo models of $\mathrm{ACC}$ in nude mice. Among the three histological patterns of ACC, the solid or cribriform pattern with distant metastasis showed intense CXCR4 staining, while the tubular or cribriform pattern without metastasis was weakly positive for CXCR4. Three patients with a solid pattern succumbed to metastases of the lung and lymph nodes.

In the in vivo model, the ACCY tumor line showed an increasing growth rate with an increase in the number of passages. The growth rate of this tumor at passage 15 was $\sim 5$-fold higher than that at passage 1 . Regarding the histological type, $\sim 30 \%$ of the cribriform pattern present at passage 1 had changed to a solid pattern at passage 15 (20). Western blot analysis showed that CXCR4 expression was $\sim 3$-fold higher at passage 15 than at passage 1 .

With the ACCI tumor line, spontaneous metastasis to the cervical lymph nodes developed at passage 2 , and the histological pattern changed from cribriform to undifferentiated carcinoma. From the metastatic lesion, we successfully established an ACCIM tumor line. This line was associated with a high frequency of spontaneous metastasis to the lung after subcutaneous transplantation in nude mice (21). Expression of CXCR4 in ACCIM was higher than that in $\mathrm{ACCI}$, and the pulmonary metastatic lesions were strongly positive for CXCR4 immunohistochemically. Although CXCR4 mRNA and protein showed negligible or low expression in normal submandibular glands, ACCIM showed a higher level of CXCR4 protein than did ACCI, and ACCI and ACCIM showed similar levels of human CXCR4 mRNA. We attributed these results to increased proteasomemediated degradation or altered gene expression at posttranslational levels. Enzymes involved in ubiquitin functioning may be rate-limiting in this process $(30,31)$. Further studies are needed to examine the direct participation of enzymes in the overexpression of CXCR4 by ACCIM tumors. 
The size of our study group was small owing to the rarity of ACC. Nonetheless, our results demonstrated close relations among CXCR4 expression, histological patterns, and metastasis in ACC. Many studies have shown that histological patterns of ACC are directly related to outcomes; the tubular pattern is associated with the best outcome and the solid pattern with the poorest. These findings suggest that the expression of CXCR4 protein may contribute to the outcomes of ACC. Thus, a high expression level of CXCR4 might be a good predictor of the risk of metastasis and of poor outcomes in patients with ACC. In addition, the inhibition of CXCR4 overexpression may be a novel targeted therapy for ACC. Currently, intense efforts are being focused on ways to identify small-molecule antagonists of chemokine receptors that may be used to treat disseminated cancer. Perhaps the response to conventional chemotherapeutic treatment can be enhanced by a combination with chemokine-receptor neutralization strategies to repress prosurvival pathways. Such strategies, developed on the basis of ongoing mechanistic studies, may lead to new possibilities for the medical management of metastatic disease.

\section{Acknowledgements}

We thank Dr T. Terada, Department of Otolaryngology, Hyogo College of Medicine, for 7 cases (Nos. 10-16) and useful discussion. This study was supported by a Grant-inAid for Scientific Research from the Ministry of Education, Culture, Sports, Science and Technology of Japan to Kazuma Noguchi (No. 16791273), Masahiro Urade (No. 18390549) and Susumu Hashitani (No. 19592343) and the Hyogo College of Medicine Research Funds.

\section{References}

1. Kokemueller H, Eckardt A, Brachvogel P and Hausamen J-E: Adenoid cystic carcinoma of the head and neck - a 20 years experience. Int J Oral Maxillofac Surg 33: 25-31, 2004.

2. Spiro RH and Huvos AG: Stage means more than grade in adenoid cystic carcinoma. Am J Surg 164: 623-628, 1992.

3. Szanto PA, Luna MA, Tortoledo ME and White RA: Histological grading of adenoid cystic carcinoma of the salivary glands. Cancer 54: 1062-1069, 1984.

4. Hamper K, Lazar F, Dietel M, et al: Prognostic factors for adenoid cystic carcinoma of the head and neck: a retrospective evaluation of 96 cases. J Oral Pathol Med 19: 101-107, 1990.

5. Sung MW, Kim KH, Kim JW, et al: Clinicopathologic predictors and impact of distant metastasis from adenoid cystic carcinoma of the head and neck. Arch Otolaryngol Head Neck Surg 129: 1193-1197, 2003.

6. Smith LC, Lane N and Rankow RM: Cylindroma (adenoid cystic carcinoma): a report of fifty-eight cases. Am J Surg 110: 519-526, 1965.

7. Muller A, Homey B, Soto H, et al: Involvement of chemokine receptors in breast cancer metastasis. Nature 410: 50-56, 2001.

8. Pablos JL, Amara A, Bouloc A, et al: Stromal-cell derived factor is expressed by dendritic cells and endothelium in human skin. Am J Pathol 155: 1577-1586, 1999.

9. Aiuti A, Webb IJ, Bleul C, Springer T and Gutierrez-Ramos JC: The chemokine SDF-1 is a chemoattractant for human CD34 $4^{+}$ hematopoietic progenitor cells and provides a new mechanism to explain the mobilization of $\mathrm{CD} 34^{+}$progenitors to peripheral blood. J Exp Med 185: 111-120, 1997.

10. Tashiro K, Tada H, Heilker R, Shirozu M, Nakano T and Honjo T: Signal sequence trap: a cloning strategy for secreted proteins and type I membrane proteins. Science 261: 600-603, 1993.
11. Bleul CC, Fuhlbrigge RC, Cassasnovas JM, Aiuti A and Springer TA: A high efficacious lymphocyte chemoattractant, stromal cell-derived factor-1 $\alpha$ (SDF-1 $\alpha$ ). J Exp Med 184: 1101-1109, 1996.

12. Campbell JJ, Hedrick J, Zlotnik A, Siani MA, Thompson DA and Butcher EC: Chemokines and the arrest of lymphocytes rolling under flow conditions. Science 279: 381-384, 1998.

13. Grabovsky V, Feigelson S, Chen C, et al: Subsecond induction of $\alpha 4$ integrin clustering by immobilized chemokines stimulates leukocyte tethering and rolling on endothelial vascular cell adhesion molecule 1 under flow conditions. J Exp Med 192: 495-506, 2000.

14. Wright N, Hidalgo A, Rodriguez-Frade JM, et al: The chemokine stromal cell-derived factor- $1 \alpha$ modulates $\alpha 4 \beta 7$ integrin-mediated lymphocytes adhesion to mucosal addressin cell adhesion molecule-1 and fibronectin. J Immunol 168: 5268-5277, 2002.

15. Ganju RK, Brubaker SA, Meyer J, et al: The $\alpha$-chemokine, stromal cell-derived factor- $1 \alpha$, binds to the transmembrane Gprotein-coupled CXCR-4 receptor and activates multiple signal transduction pathways. J Biol Chem 273: 23169-23175, 1998.

16. Homey B, Muller A and Zlotnik A: Chemokines: agents for the immunotherapy of cancer? Nat Rev Immunol 2: 175-184, 2002.

17. Cardones AR, Murakami T and Hwang ST: CXCR4 enhances adhesion of B16 tumor cells to endothelial cells in vitro and in vivo via B (1) integrin. Cancer Res 63: 6751-6757, 2003

18. Murakami T, Maki W, Cardones AR, et al: Expression of CXC chemokine receptor-4 enhances the pulmonary metastatic potential of murine B16 melanoma cells. Cancer Res 62: 7328-7334, 2002.

19. Robledo MM, Bartolome RA, Longo N, et al: Expression of functional chemokine receptor CXCR3 and CXCR4 on human melanoma cells. J Biol Chem 276: 45098-45105, 2001.

20. Hashitani S, Noguchi K, Manno Y, et al: Changes of histological and biological features by serial passages in a human adenoid cystic carcinoma line transplantable in nude mice. Oncol Rep 13: 607-612, 2005.

21. Hashitani S, Urade M, Zushi Y, Segawa E, Okui S and Sakurai K: Establishment of nude mouse transplantable model of a human adenoid cystic carcinoma of the oral floor showing metastasis to the lymph node and lung. Oncol Rep 17: 67-72, 2007.

22. Sobin LH and Wittekind C: UICC: TNM Classification of Malignant Tumours. 6th edition. John Wiley \& Sons, New York, 2002.

23. Barnes L, Eveson J W, Reichart P and Sidransky D: The WHO's classification of Tumours: Pathology and Genetics of the Head and Neck Tumours. IARC Press, Lyon, 2005.

24. Hsu SM, Raine L and Franger H: Use of avidin-biotinperoxidase complex $(\mathrm{ABC})$ in immunoperoxidase techniques: a comparison between $\mathrm{ABC}$ and unlabeled antibody (PAP) procedures. J Histochem Cytochem 29: 577-580, 1981.

25. Shirozu M, Nakano T, Inazawa J, Tashiro K, Tada H, Shinohara T and Honjo T: Structure and chromosomal localization of the human stromal cell-derived factor-1 (SDF-1) gene. Genomics 28: 495-500, 1995.

26. Uchida D, Begum NM, Almofti A, et al: Possible role of stromal-cell-derived factor-1/CXCR4 signaling on lymph node metastasis of oral squamous cell carcinoma. Exp Cell Res 290: 289-302, 2003.

27. Uchida D, Begum NM, Tomizuka Y, et al: Acquisition of lymph node, but not distant metastatic potentials, by the overexpression of CXCR4 in human oral squamous cell carcinoma. Lab Invest 84: 1538-1546, 2004.

28. O'Donnell RK, Kupferman M, Wei SJ, et al: Gene expression signature predicts lymphatic metastasis in squamous cell carcinoma of oral cavity. Oncogene 24: 1244-1251, 2004.

29. Müller A, Sonkoly E, Eulert C, et al: Chemokine receptors in head and neck cancer: association with metastatic spread and regulation during chemotherapy. Int J Cancer 118: 2147-2157, 2006.

30. Haas AL: Introduction: evolving roles for ubiquitin in cellular regulation. FASEB J 11: 1053-1054, 1997.

31. Rolfe M, Chiu MI and Pagano M: The ubiquitin-mediated proteolytic pathway as a therapeutic area. J Mol Med 75: 5-17, 1997. 